\title{
Structural Analysis for Estimating Damage Behavior of Double Hull under Ice-Grounding Scenario Models
}

\author{
Aditya Rio Prabowo ${ }^{1, a^{*}}$, Jung Min Sohn ${ }^{2, b}$, Jung Hoon Byeon ${ }^{2, c}$, \\ Dong Myung Bae ${ }^{2, \mathrm{~d}}$, Ahmad Fauzan Zakki ${ }^{3, \mathrm{e}}$, Bo Cao ${ }^{4, \mathrm{f}}$ \\ ${ }^{1}$ Interdisciplinary Program of Marine Convergence Design, Pukyong National University, \\ Busan 48513, South Korea
}

2Department of Naval Architecture and Marine Systems Engineering, Pukyong National University, Busan 48513, South Korea

\author{
${ }^{3}$ Department of Naval Architecture, Diponegoro University, Semarang 50268, Indonesia \\ ${ }^{4}$ China Shipbuilding Industry Corporation Economic Research Center, Beijing 100012, China

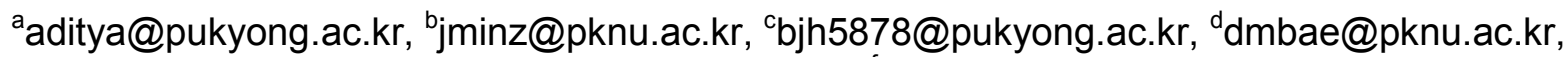 \\ eahmadfzakki@gmail.com, ${ }^{\mathrm{f}} \mathrm{csiccb} @ 163 . c o m$
}

Keywords: Grounding impact; Grounded ice; FE simulation; Internal energy; Structural failure

\begin{abstract}
Demand to increase safety for water transportation, namely ship is continuously rising as various accidental loads may threat condition of target structure, i.e. ship. Several possibilities of impact scenario can occur with various indenters, for example stranding to a grounded ice. In this work, a study of structural behaviour accounting for interaction between the ship structure and indenter is conducted. Numerical simulation is performed using finite element method to estimate damage extent of the double bottom. In analysis, the indenter for grounding scenario is applied by characteristic of the ice properties to obtain estimated response of the structure in experiencing impact on polar territory. Impact scenario is defined into three different locations, namely girder and space between two girders. Finally, tendency of the damage per destroyed component is summarized.
\end{abstract}

\section{Introduction}

Since the exploration and research to the North Pole has been conducted in the early 2000 and the treaty of several countries in Northern Europe to open Bering Strait for sailing route, the Northern Sea Route (NSR) is preferred to be used for transporting commodities from Eastern Asia to Northern and Western Europe. In his study, Cao et al. [1] mentioned that the NSR is evidenced capable to reduce sailing distance from Asia to Europe, which specifically it can save operational cost and delivery time. However, these advantages come with serious challenge and risk. Possibility of ships to contact with ice and seabed in form of collision [2-4] and grounding [5,6] may be unavoidable. According to statistical data of International oil Pollution Compensation Fund (IOPCF), grounding surpasses fire, corrosion, and breaking in term of main cause of large oil spill from tankers [7]. The possibility of environmental damage on the polar territory may take place and extinction of wildlife there can affect earth massively. Development in calculation methods makes numerical calculation is deployed to be used in estimating various phenomena in science and engineering. Previous researchers [8-10] concluded that the finite element (FE) method is powerful enough to produce estimated results for nonlinear phenomenon, i.e. collision between ships and grounding with seabed.

In this study, the analysis is expanded into other possibility where ship grounding may happen in the polar territory, which grounded ice acts as the indenter in this event. A chemical tanker is modelled to provide adequate representative regarding carrier of dangerous commodities which will pollute ocean and polar environments after grounding. The analysis is conducted to obtain behavior estimation in grounding process and damage extent in the end of impact. Contribution of involved components in each grounding scenario is presented to observe influence extent of the indenter on the double-bottom structure and evaluate safety of the inner part which contains transported cargo. 


\section{Theoretical Basis of Grounding phenomenon}

Estimation of Impact Frequency. Quantification of frequency and consequence are two important matters that should be quantified as societal acceptance limits. If governments and regulatory bodies are seriously considered to build rules for design, estimation of the accident frequency becomes vital matter as engineered design performance is also measured using accidental data of the design when it is used widely by society. Related to ship grounding, risk model was introduced by Fujii [11] since before 1990. In middle of the nineties, Pedersen [12] classified the scenario that leads to grounding phenomenon into four main classes.

Global Deformation Kinematics. Since principle structural elements are attached to the shell or the inner bottom platting [13], it is convenient to use the deformation of the platting as the subject for discussion in the global deformation mode. Based on this illustration, we obtain that in grounding process, the hull platting may get deformed with two possibilities, with and without fracture. Material elements of the subject will experience bending, stretching, and fracture depend on the deformation mode which lead to the difference of the deformation zone and energy dissipation in each of the three mechanisms. Longitudinal and transverse gap openings $u_{0}$ and $v_{0}$ in damage pattern are respectively given by Equations 1 and 2 .

$$
\begin{aligned}
& u_{0}=B_{d e} \sqrt{(1-\cos \alpha)^{2} \sin ^{2} \theta+(1-\cos \theta)^{2} \sin ^{2} \alpha} \\
& v_{0}=B_{d e}(1 / \cos \alpha-1)
\end{aligned}
$$

\section{Ship Grounding}

Engineering Model. The ship is modelled after 17,000 ton non-ice class chemical tanker with principal dimensions $144 \mathrm{~m}$ in length, $22.60 \mathrm{~m}$ in width, and $12.50 \mathrm{~m}$ in total height. The ship is applied high strength-low alloy steel with characteristic of the plastic-kinematics material [3] is implemented on them. The grounded ice is defined as rigid ice entity which refer to Gagnon's model [14]. The indenter is idelized as small part of an grounded ice in polar territory. The model is built similar to a conical form with total height $0.60 \mathrm{~m}$, maximum width $1.20 \mathrm{~m}$ and elevation angle $45^{\circ}$.

Configuration of Grounding Simulation. The ship model and indenter topology are built for numerical simulation using fully integrated Belytschko-Tsay element formulation which is calculated by nonlinear finite element code ANSYS LS-DYNA. The space between the ship and grounded ice is determined $0.1 \mathrm{~m}$ and in the end of the ship model, restriction for axial and rotational displacement is applied. Contact between two entities is defined as impact of the grounded ice to the double-bottom structure of the tanker ship, which deploys friction coefficient 0.07 . In grounding process, the indenter moves with the applied velocity $10 \mathrm{~m} / \mathrm{s}$ into the three designated locations, namely the center girder, side girder, and space between girders with grounding time is determined $0.40 \mathrm{~s}$.

\section{Results and Discussions}

After observation is conducted on the simulation results in Figures 1 to 3, it is concluded that the center structure is the strongest arrangement on the double-bottom structure. The center structure successfully provided the best resistance against penetration of the grounded ice as indicated by the rupture energies' behavior. This energy is defined as the energy that is needed to plastically deform or even destroy the involved structures in impact. This energy is also called by other name in pioneer works, such as internal energy, absorbed strain energy, collision energy, etc. Tendency of the rupture provided an estimation that according to the proposed scenario models in this study, the bottom part experienced the most intense damage, which high magnitudes were produced by the structural components in this side. This behavior is verified with the damage extent in the next discussion. 

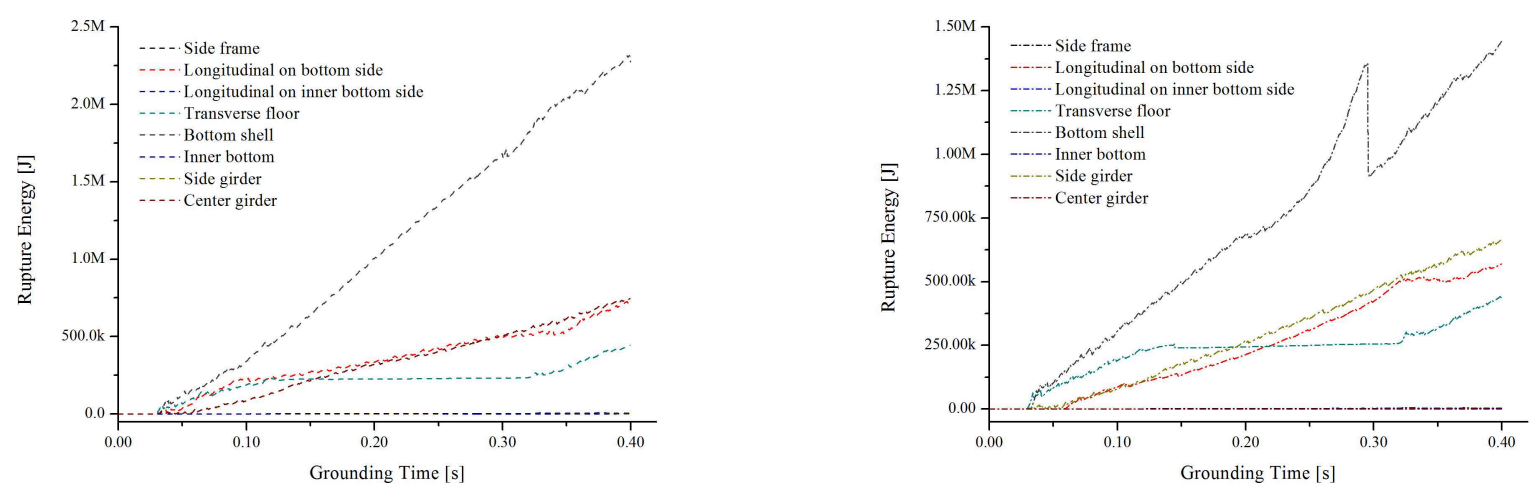

Fig. 1 Structural response in grounding to the center girder. Fig. 2 Structural response in grounding to the side girder.

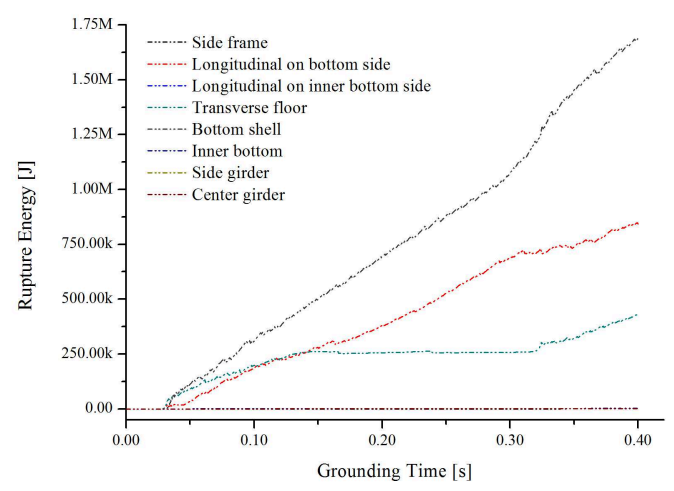

Fig. 3 Structural response in grounding to the space between center and side girders.

In cumulative calculation of the rupture energy, it is concluded that the critical location is the space between two girders as in this location there is no longitudinal structure that strong enough to resist the penetration of the indenter like the girders. This condition affected stress contour of the double-bottom structure under impact. The von Mises stress in Figures 4 to 6 indicate that during grounding process to the space between girders, the stress spread farther than the moment grounding occurred on the girders. The high-stress contour was also spotted on three longitudinal in this grounding model.

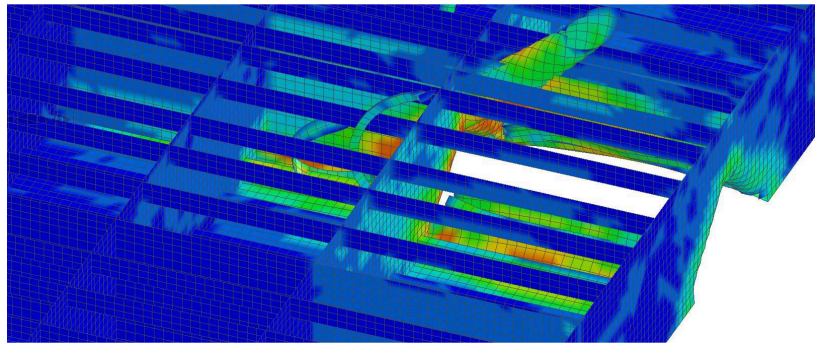

Fig. 4 Stress contour on the center girder.

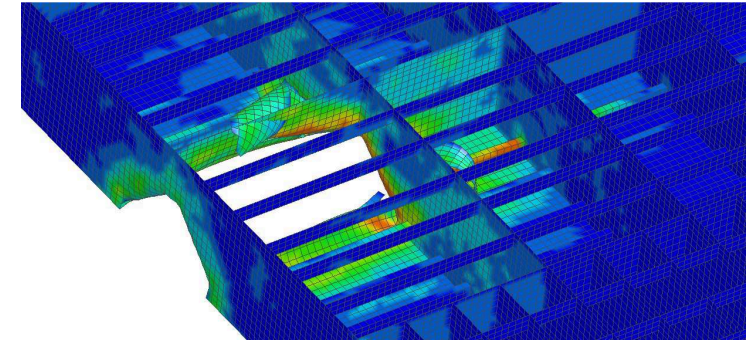

Fig. 5 Stress contour on the side girder.

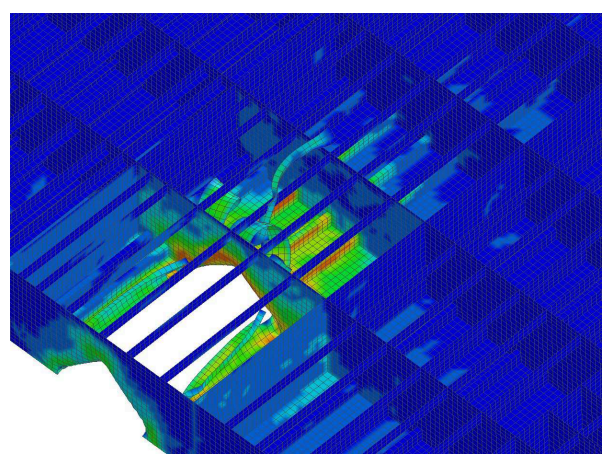

Fig. 6 Stress contour on the space between center and side girders. 


\section{Conclusion}

This paper presented structural estimation of a double-bottom structure under several scenarios of grounding impact. Serious attention and countermeasure should be paid during impact occurs on the space between girders. According to the tendency, in grounding model which impact occurred on the girders, the stress only reached the space between the third and fourth transverse floors. However, in the third case which impact took place to the space between girders, the von Mises contour was observed surpassed the fourth floor and almost reached the fifth one relative to the longitudinal axis or $x$-direction in the Cartesian coordinate system. This situation concluded that the initial rupture of the space-grounding model is more advance and may cause immense damage on the bottom part.

\section{Acknowledgement}

This work was successfully published with the grant from BK21 plus MADEC Human Research Development Group, Republic of Korea.

\section{References}

[1] B. Cao, D.M. Bae, J.M. Sohn, A.R. Prabowo, T.H. Chen, H. Li, Numerical analysis for damage characteristics caused by ice collision on side structure, The $35^{\text {th }}$ International Conference on Ocean, Offshore and Arctic Engineering (2016), Busan, South Korea.

[2] A.R. Prabowo, D.M. Bae, J.M. Sohn, A.F. Zakki, B. Cao, Rapid prediction of damage on a struck ship accounting for side impact scenario models, Open Engineering. 7 (2017) 1-9.

[3] A.R. Prabowo, D.M. Bae, J.M. Sohn, A.F. Zakki, B. Cao, Q. Wang, Analysis of structural behavior during collision event accounting for bow and side structure interaction, Theoretical and Applied Mechanics Letters. 7 (2017) 6-12.

[4] A.R. Prabowo, D.M. Bae, J.M. Sohn, B. Cao, Energy behavior on side structure in event of ship collision subjected to external parameters, Heliyon. 2 (2016) e00192.

[5] A. AbuBakar, R.S. Dow, Simulation of ship grounding damage using the finite element method, International Journal of Solids and Structures. 50 (2013) 623-636.

[6] O.V.E Sormunen, M. Kõrgesaar, K. Tabri, M. Heinvee, A. Urbel, P. Kujala, Comparing rock shape models in grounding damage modelling, Marine Structures. 50 (2016) 205-223.

[7] IOPCF, International Regime for Compensation for Oil Pollution Damage, IOPCF (2006).

[8] D.M. Bae, A.R. Prabowo, B. Cao, J.M. Sohn, A.F. Zakki, Q. Wang, Numerical simulation for the collision betweem side structure and level ice in event of side impact scenario, Latin American Journal of Solids and Structures. 13 (2016) 2991-3004.

[9] H.S. Alsos, J. Amdahl, On the resistance of tanker bottom structures during stranding, Marine Structures. 20 (2007) 218-237.

[10] A.R. Prabowo, D.M. Bae, J.M. Sohn, A.F. Zakki, B. Cao, J.H. Cho, Effects of the rebounding of a striking ship on structural crashworthiness during ship-ship collision, Thin-Walled Structures. 115 (2017) 225-239.

[11] Y. Fujii, R. Shiobara, The analysis of traffic accidents, Journal of Navigation. 24 (1971) 534543.

[12] P.T. Pedersen, Collision and grounding mechanics, Danish Society of Naval Architecture. (1995) 125-158.

[13] B.C. Simonsen, Mechanics of ship grounding, Doctoral thesis, Department of Naval Architecture and Offshore Engineering, Technical University of Denmark, (1997).

[14] R.E. Gagnon, J. Wang, Numerical simulations of a tanker collision with a bergy bit incorporating hydrodynamics, a validated ice model and damage to the vessel, Cold Regions Science and Technology. 81 (2012) 26-35. 